\title{
Evaluation of a Semiempirical, Zero-Dimensional, Multizone Model to Predict Nitric Oxide Emissions in DI Diesel Engines' Combustion Chamber
}

\author{
Nicholas S. Savva and Dimitrios T. Hountalas \\ Internal Combustion Engines Lab, National Technical University of Athens, Zografou Campus, \\ 9 Heroon Polytechniou, 15780 Athens, Greece
}

Correspondence should be addressed to Nicholas S. Savva; nichosavv@hotmail.com

Received 30 November 2015; Accepted 7 February 2016

Academic Editor: Satyanarayanan R. Chakravarthy

Copyright (c) 2016 N. S. Savva and D. T. Hountalas. This is an open access article distributed under the Creative Commons Attribution License, which permits unrestricted use, distribution, and reproduction in any medium, provided the original work is properly cited.

\begin{abstract}
In the present study, a semiempirical, zero-dimensional multizone model, developed by the authors, is implemented on two automotive diesel engines, a heavy-duty truck engine and a light-duty passenger car engine with pilot fuel injection, for various operating conditions including variation of power/speed, EGR rate, fuel injection timing, fuel injection pressure, and boost pressure, to verify its capability for Nitric Oxide (NO) emission prediction. The model utilizes cylinder's basic geometry and engine operating data and measured cylinder pressure to estimate the apparent combustion rate which is then discretized into burning zones according to the calculation step used. The requisite unburnt charge for the combustion in the zones is calculated using the zone equivalence ratio provided from a new empirical formula involving parameters derived from the processing of the measured cylinder pressure and typical engine operating parameters. For the calculation of NO formation, the extended Zeldovich mechanism is used. From this approach, the model is able to provide the evolution of NO formation inside each burned zone and, cumulatively, the cylinder's NO formation history. As proven from the investigation conducted herein, the proposed model adequately predicts $\mathrm{NO}$ emissions and NO trends when the engine settings vary, with low computational cost. These encourage its use for engine control optimization regarding $\mathrm{NO}_{x}$ abatement and real-time/model-based $\mathrm{NO}_{x}$ control applications.
\end{abstract}

\section{Introduction}

Pollution and hence human health and life quality deterioration [1] due to exhaust emissions from vehicles have become a severe problem especially in populated areas and large cities. To mitigate pollution from this source, strict regulations [2] have been applied forcing the internal combustion engines (ICE) industry to reduce such harmful emissions. Hence, the ICE manufacturers invest on technologies of exhaust emissions control, in order to comply with the regulations and guarantee their presence in the markets.

There exist various methodologies to achieve exhaust emissions abatement $[1,3]$ such as engine development for low emissions (in-cylinder emission control) and/or use of after-treatment technologies. A useful tool to assist their development and application is the use of simulation models, due to their ability to predict exhaust emissions. Considering that Nitric Oxides $\left(\mathrm{NO}_{x}\right)$ is one of the most important controlled pollutants of Diesel engines, authors were motivated to evolve a recently developed simplified model [4] for the prediction of $\mathrm{NO}$ emissions (predominant of $\mathrm{NO}_{x}$ ) for various engine settings/configurations and engine types.

According to the relevant literature, various types of models for exhaust emissions prediction have been reported. A common type of model used for $\mathrm{NO}_{x}$ prediction is the multizone phenomenological models [5-7]. These models employ the fuel injection rate accompanied with phenomenologi$\mathrm{cal} /$ semiempirical relations for combustion mixture preparation and spray characteristics. Alternatively CFD models $[8,9]$ can be used, because they are able to realistically describe the in-cylinder phenomena temporally and spatially because they are based on fundamental physics. However 
both model types, and especially the CFD ones, have significantly increased computational cost which makes them inappropriate for real-time applications. In addition, they present high complexity and calibration demands and are difficult to handle. These limit the prospective for their implementation in practical applications (e.g., model-based control). A solution for this could be the use of singlezone models [10-12] which are very fast and simple, but because of their single-zone concept, they can provide only the average cylinder temperature (and conditions) which alone cannot be utilized for $\mathrm{NO}_{x}$ formation calculation. To overcome this drawback, zero-dimensional, two-zone [13-15] or multizone [16-18] models can be used. Furthermore, fully empirical/statistical [19-21] or semiempirical models [22-27] which present very low computational cost can be employed. However, for the calibration of these models (i.e., coefficients determination) a comprehensive experimental database is required, but even then, due to the lack of physical base, they can provide adequate predictions only inside the range that they have been calibrated.

Considering the pros and cons of the aforementioned model types along with the industry requirement for fast, simplified, versatile, and reliable $\mathrm{NO}_{x}$ prediction models, with low calibration demands and easy handling/application, the authors have developed a model for NO prediction by following a zero-dimensional, multizone approach. The model had been implemented on a limited number of operating points of two different DI Diesel engines (a heavyduty truck engine and a light-duty car engine) [28, 29]. In the present work, an effort has been made to improve model's predictive ability by enhancing its physical base and expanding its implementation range. For this reason, the new model was further validated on additional operating points and engine configurations/settings of the aforementioned engines. Namely, the capability of the model to predict NO trends with engine load, injection timing, injection pressure, EGR rate, and boost pressure variation is evaluated. It is also noted that the model has been previously implemented on a number of 4- and 2-stroke large-scale DI Diesel engines, providing adequate results as reported in [4].

The proposed model uses the measured cylinder pressure to calculate the apparent combustion rate via heat release rate (HRR) analysis, which is then discretized into combustion zones according to the calculation step (in crank angle degrees). The zones are autonomous and are evolving inside the cylinder as the time elapses following the first law of thermodynamics. NO formation inside each zone is calculated via extended Zeldovich mechanism.

Some models that follow similar concepts can be found in literature [30-32] which, however, are much more complicated because they use phenomenological/semiempirical formulas for fuel/air mixing, air entrainment, heat and mass transfer, and so forth, and so forth, which require significant calibration effort for different engine characteristics and operating conditions. This, limits the model's implementation range. On the contrary, the proposed model does not follow the common approach of air entrainment rate (continuous air entrainment inside the zone) during the engine cycle as suggests the spray evolution theory $[8,33,34]$. Instead, the unburnt charge is distributed to each zone at the time of its generation. The amount of the distributed unburnt charge to each zone is calculated from the zone equivalence ratio $(\Phi)$ and from the amount of fuel attributed to each zone. $\Phi$ is assumed to be constant for all zones but varies with engine operating conditions. The value of $\Phi$ is calculated only once during the cycle by using a simple empirical correlation. This feature minimizes model's complexity, computational cost, and calibration effort and at the same time improves model's prediction ability. Thus, in the proposed model a combination of physical and empirical concepts is made, which allows, as shown later in the text, achieving satisfactory tailpipe NO predictions. From the results, models' suitability for both research and practical/field applications is evaluated.

\section{Presentation of the Proposed Model}

The model presented herein is a physically based, zerodimensional multizone one, for the prediction of NO emissions from Diesel engines by using as input the measured cylinder pressure. Alternatively, a calculated in-cylinder pressure can be used, derived from well validated single-zone models which, as mentioned, do not have NO prediction capabilities.

At first, the charge conditions before combustion commencement are calculated accounting for the cylinder residual gas (RG) fraction, EGR rate, and intake air mass flow. Then, the apparent combustion rate is calculated via HRR analysis using the measured cylinder pressure. Afterwards, the NO model is implemented at the time period from the start of combustion (SOC) up to exhaust valve opening (EVO).

The model's concept is described schematically in Figure 1. Each filled symbol corresponds to the generation of a combustion zone. The fuel attributed to each zone is derived from the discretization of combustion rate according to the crank angle (CA) calculation step. The unburnt charge mass (air + EGR + RG) amount used at the zone generation is determined from the zone equivalence ratio $(\Phi)$ and the corresponding zone fuel amount. Complete/homogenous mixing of the fuel and unburnt charge is assumed. By this approach, the employment of spray models (e.g., phenomenological multizone) or/and space geometrical discretization (e.g., mesh) is avoided. After their generation, the combustion zones are being compressed/expanded (empty squares in Figure 1), according to the pressure derivative, inside the cylinder until EVO. The zones are autonomous and do not exchange mass and heat between them. NO is formed inside each zone from its generation up to EVO by using the extended Zeldovich mechanism. Via this concept, the evolution of zone NO formation inside the cylinder, during an engine cycle, is provided. The cumulative NO from the zones at each calculation CA step provides the overall evolution of NO formation as shown in Figure 2.

\section{Basic Calculations}

3.1. Initial Conditions. The initial conditions required from the model are the in-cylinder trapped mass (unburnt charge) 


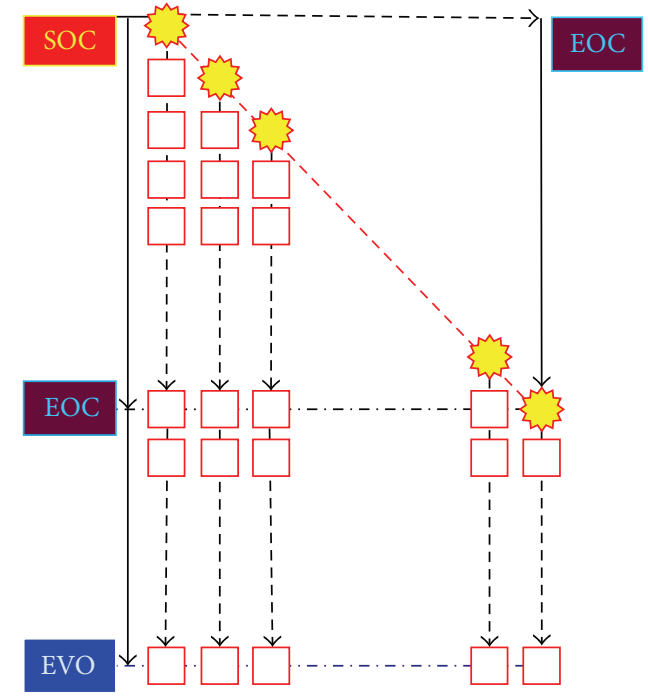

FIgURE 1: The multizone approach for the NO calculation [4].

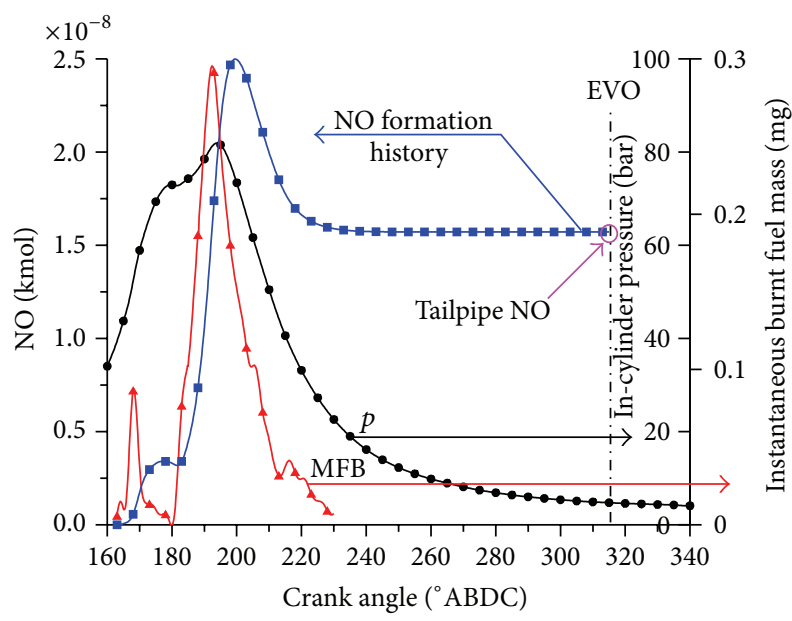

FIGURE 2: NO formation history inside the combustion chamber during an engine cycle along with cylinder pressure and fuel amount burnt at each CA step.

and its composition and temperature at combustion commencement. The trapped mass $\left(\dot{m}_{\mathrm{tr}}[\mathrm{g} / \mathrm{cycle}]\right)$ is assumed to be unchanged from intake valve closure (IVC) up to SOC-1. Its composition is considered constant throughout the cycle assuming no interaction between the zones. The trapping efficiency is assumed to be equal to unity (realistic for 4-stroke engines) [34] and thus the trapped mass is calculated from (1) by using the following inputs: number of cylinders $\left(n_{\text {cyl }}\right)$, engine speed $(N[\mathrm{rpm}])$, intake air mass flow $\left(\dot{m}_{\mathrm{IA}}[\mathrm{kg} / \mathrm{h}]\right)$, and EGR and RG mass fractions:

$$
\dot{m}_{\mathrm{tr}}=\frac{\dot{m}_{\mathrm{IA}} \cdot 100 / 3}{n_{\mathrm{cyl}} \cdot N} \cdot \frac{1+\mathrm{RG}}{1-\mathrm{EGR}} .
$$

In the present work, the experimental data for $\dot{m}_{\mathrm{IA}}$, EGR rate, and RG fraction were supplied from external provider. Here, it is noted that the values of $\dot{m}_{\mathrm{IA}}$ and EGR rate (EGR valve position) can be reliably measured "on-board" in real-time and RG fraction can be estimated using simplified models. Furthermore, these parameters can be obtained from the ECU since they can be mapped as functions of engine speed and load. Alternatively, $\dot{m}_{\mathrm{IA}}$ could be estimated directly using the measured pressure and temperature at intake manifold and the cylinder pressure, via a simplified zero-dimensional model $[35,36]$, or indirectly from the exhaust gas oxygen content.

The composition of EGR and RG gases is assumed to be identical to the one of the exhaust gas which is calculated by assuming ideal combustion using the global $\Phi$ and accounting for the fuel composition $(\mathrm{H} / \mathrm{C})$. The composition of the unburnt charge is calculated using the EGR, RG, and ambient air mass fractions and compositions. Using the trapped mass, its composition (molecular weight (MW)), and the corresponding cylinder pressure and volume via the ideal gas state equation, the unburnt charge temperature at SOC1 is provided. This temperature serves as the initial value for the calculation of unburnt zone temperature.

3.2. Utilizing the Measured Cylinder Pressure and HRR. The processes evolving inside the engine cylinder are directly or implicitly reflected on the measured cylinder pressure [34]. From these processes that involve compression, fuelair mixing, combustion, expansion, and so forth, the thermodynamic condition of the charge, which affects $\mathrm{NO}_{x}$ formation mechanism, is determined. Moreover, the effect of heat transfer, leakages, inlet conditions, turbulence, fuel-air mixing, engine geometry, and so forth on these mechanisms is also implicitly accounted for when the actual cylinder pressure is used. Furthermore, the effect of injection strategy (pilot/post, multiple injection) is implicitly accounted for because the actual cylinder pressure and combustion rate (i.e., HRR) are used. Thus, the use of measured cylinder pressure adds versatility to the model since the variations occurring inside the cylinder, and having an effect on NO formation, can be captured.

As mentioned, the combustion rate (i.e., fuel amount $\left(m_{f}\right)$ combusted at each time (CA) step; e.g., see Figure 2) is calculated directly from HRR, assuming instantaneous combustion, as shown in (2) ( $d p$ is derived from the measured cylinder pressure), by dividing the gross heat release $\left(d Q_{\text {gross }}[\mathrm{J}]\right)$ by the fuel lower heating value $(\mathrm{LHV}[\mathrm{J} / \mathrm{kg}])$ as described in (3):

$$
\begin{aligned}
\frac{d Q_{\text {gross }}}{d \mathrm{CA}} & =\frac{d H_{\text {sens }}}{d \mathrm{CA}}-V \cdot \frac{d p}{d \mathrm{CA}}+\frac{d \mathrm{Q} w}{d \mathrm{CA}}, \\
m_{f} & =\frac{d \mathrm{Q}_{\text {gross }} / d \mathrm{CA} \cdot \Delta \mathrm{CA}}{\mathrm{LHV}} .
\end{aligned}
$$

For the heat exchange $\left(d \mathrm{Q} w / d \mathrm{CA}\left[\mathrm{J} /{ }^{\circ} \mathrm{CA}\right]\right)$ through the cylinder wall, the Annand formula has been used $[34,37]$ due to the less computational cost and calibration effort required compared to the Woschni [38] model. Detailed description of the HRR calculations is presented in [4]. 
3.3. Unburnt Zone Evolution inside the Cylinder. The chemical composition of the unburnt zone is assumed to be constant for the entire closed cycle; namely, it does not interact with the combustion zones. When combustion commences, the requisite unburnt charge amount for the combustion during zone formation is obtained from the unburnt zone. Thus the unburnt zone mass is consumed as combustion persists. The volume $\left(V_{\mathrm{ub}}\left[\mathrm{m}^{3}\right]\right)$ of the unburnt zone at each calculation step is calculated by subtracting the volumes of the existing combustion zones from the current cylinder volume. Its temperature, which corresponds to reactants' temperature during combustion at zone generation, is calculated by using the first law of thermodynamics at each CA step

(i) following an iterative procedure. This procedure involves (4) for the enthalpy calculation and (5) (Newton-Raphson [39] method) for the temperature calculation:

$$
\begin{aligned}
h_{i}^{k} & =\frac{n_{i-1} \cdot h_{i-1}+d p_{i} \cdot\left(V_{i-1}+V_{i}\right) / 2-n_{\text {out }} \cdot\left(h_{i-1}+h_{i}^{k-1}\right) / 2-d Q w_{i}^{k}}{n_{i}}, \quad n_{i}=n_{i-1}-n_{\text {out }}, \\
T_{i}^{k} & =T_{i}^{k-1}-\frac{h_{i}^{k}-h_{i}^{k-1}}{c p_{i}^{k-1}} .
\end{aligned}
$$

In the previous expressions $n[\mathrm{kmol}]$ is the number of moles comprised in the unburnt zone and is calculated by subtracting from the number of moles of the previous CA step the moles required from the zone $\left(n_{\text {out }}[\mathrm{kmol}]\right)$, which is generated at the current CA step. Furthermore, $d Q w[\mathrm{~J}]$ corresponds to the heat transfer through the cylinder wall calculated using Annand's model [37] where the current incylinder area is multiplied by $V_{\mathrm{ub}, i}^{k} / V \mathrm{cyl}_{i}$ to fairly represent the equivalent zone area. Superscript $k$ denotes the iteration sequence number. Detailed description of the heat transfer through the cylinder wall method used can be found in [4].

3.4. Generation and Evolution of the Combustion Zones. In order to consider convincingly the local conditions (i.e., temperature, species concentration) inside the combustion chamber, which determine the NO formation [34, 40, 41], a multizone approach is adopted (see Figure 1).

The mass of each zone $(m[\mathrm{~kg}])$, after its generation, remains constant throughout the cycle since the zones do not interact. The pressure inside the zones coincides with the measured cylinder pressure. Zone temperature $(T p[K])$ is determined by the use of the first law of thermodynamics via a Newton-Raphson [39] iterative methodology described in

$$
\begin{aligned}
T p_{z, i}^{k}= & T p_{z, i}^{k-1} \\
& -\frac{h p_{z, i}^{k-1}-h r_{z, i}+d q w_{z, i}^{k-1}-V_{z, i}^{k-1} \cdot d p_{i} / m_{z}}{c p_{z, i}^{k-1}} .
\end{aligned}
$$

Zone composition is derived from the combustion of the fuel and the corresponding unburnt charge, accounting for chemical dissociation (see Section 3.5) of combustion products. For the calculation of enthalpy before combustion $(\mathrm{hr}[\mathrm{J} / \mathrm{kg}])$, the reactants' temperature $(\operatorname{Tr}[\mathrm{K}])$ and composition are used, which are equal to the ones of the unburnt charge at the examined CA step (see Section 3.3). On the other hand, enthalpy after combustion $(h p[\mathrm{~J} / \mathrm{kg}])$ is a function of $T p$ and combustion products composition. Zone volume $\left(V\left[\mathrm{~m}^{3}\right]\right)$ is calculated via the ideal gas state equation. $d q w[\mathrm{~J} / \mathrm{kg}]$ corresponds to the heat transfer between the zone and cylinder wall and is calculated using Annand's model [37] similarly to the unburnt zone calculation (see Section 3.3).

After its formation, the zone evolves throughout the close engine cycle following the first law of thermodynamics and according to the cylinder pressure evolution. Therefore, at each CA step ( $i$ ), the values of volume, composition, enthalpy, and temperature of the examined zone $(z)$ are calculated iteratively. The enthalpy $(h)$ and temperature $(T)$ of each zone $(z)$ are calculated from the following equations, respectively:

$$
\begin{aligned}
& h_{z, i}^{k}=\frac{n_{z, i-1} \cdot h_{z, i-1}+d p_{i} \cdot\left(V_{z, i-1}+V_{z, i}^{k}\right) / 2-d Q w_{z, i}^{k}}{m_{z} / \mathrm{MW}_{z, i}^{k}}, \\
& T_{z, i}^{k}=T_{z, i}^{k-1}-\frac{h_{z, i}^{k}-h_{z, i}^{k-1}}{c p_{z, i}^{k-1}} .
\end{aligned}
$$

Apparently, the initiation values for the iteration at each CA step equal the respective final ones of the previous step. When the zone temperature $(T)$ converges, the calculation procedure proceeds to the next CA step.

3.5. Chemical Dissociation Mechanism. The calculation of zone temperature accounts for the combustion products dissociation. This mechanism results in a noticeable decrease of combustion temperature since most of its reactions are endothermic. Furthermore, for the zone equilibrium composition calculation, the proposed model uses a chemical dissociation scheme [42-44], which involves 11 chemical species $\left(\mathrm{O}_{2}\right.$ for fuel lean or $\mathrm{C}_{12} \mathrm{H}_{26}$ for fuel rich, $\mathrm{N}_{2}, \mathrm{CO}_{2}, \mathrm{H}_{2} \mathrm{O}, \mathrm{H}, \mathrm{H}_{2}$, $\mathrm{N}, \mathrm{NO}, \mathrm{O}, \mathrm{OH}, \mathrm{CO}$ ), seven equilibrium reactions, and the four conservation equations describing the combustion for the $\mathrm{C} / \mathrm{H} / \mathrm{O} / \mathrm{N}$ system. Equilibrium composition is utilized during the NO formation calculation described next. Equilibrium constants are derived from minimization of the Gibbs free energy of the chemical reactions used. This scheme has been described in detail in previous publications $[4,28,29]$ of the authors. 
3.6. Calculation of Nitric Oxide Formation. In the present study only the thermal $\mathrm{NO}_{x}$ formation mechanism is considered (i.e., NO formation), since this mechanism is predominant at high-temperature, stoichiometric diffusion flame which characterizes DI Diesel combustion [34, 40, 45].

Due to the higher time required for $\mathrm{NO}$ formation compared to the time available for combustion processes inside the combustion chamber of DI Diesel engines, NO rarely reaches equilibrium. Hence, $\mathrm{NO}$ formation is kinetically controlled $[34,41]$ while equilibrium concentration is assumed for the remaining species. Therefore, the extended Zeldovich mechanism [34, 40, 46, 47] has been used, which is described from the three reactions shown in

$$
\begin{gathered}
\mathrm{O}+\mathrm{N}_{2} \stackrel{R_{1}}{\longleftrightarrow} \mathrm{NO}+\mathrm{N} \\
\mathrm{N}+\mathrm{O}_{2} \stackrel{R_{2}}{\longleftrightarrow} \mathrm{NO}+\mathrm{O} \\
\mathrm{N}+\mathrm{OH} \stackrel{R_{3}}{\longleftrightarrow} \mathrm{NO}+\mathrm{H}
\end{gathered}
$$

Their reaction rate constants, which are functions of temperature and used for the reaction rates calculation $\left(R_{1,2,3}\left[\mathrm{kmol} / \mathrm{m}^{3} / \mathrm{s}\right]\right)$, are derived from [48].

NO formation rate is calculated from (10), which is derived from the mathematical processing $[40,41]$ of the differential equations that describe the kinetics of the extended Zeldovich mechanism:

$$
\begin{aligned}
\left(\frac{d \mathrm{NO}}{d \mathrm{CA}}\right)_{z, i}= & \left(\frac{d[\mathrm{NO}]}{d t}\right)_{z, i} \cdot V_{z, i} \cdot \frac{d t}{d \mathrm{CA}} \\
= & \frac{2 \cdot R_{1} \cdot\left\{1-\left([\mathrm{NO}] /[\mathrm{NO}]_{e}\right)^{2}\right\}}{1+\left([\mathrm{NO}] /[\mathrm{NO}]_{e}\right) \cdot R_{1} /\left(R_{2}+R_{3}\right)} \\
& \cdot \frac{V_{z, i}}{6 \cdot N}
\end{aligned}
$$

In the previous expression, $V_{z, i}\left[\mathrm{~m}^{3}\right]$ is the zone $(z)$ volume at the examined CA step (i). The integration of (10) in the CA domain until EVO provides the $\mathrm{NO}[\mathrm{Kmol}]$ amount formed inside each zone and cumulatively inside the cylinder, at each CA step.

Comprehensive description of the model can be found in [4]. In the present work, an improved correlation for zone equivalence ratio $\Phi$ is introduced, as presented next, in order to enhance model's NO prediction capability.

3.7. Calculation of Zone Equivalence Ratio $\Phi$. According to the model's rationale (see Section 2), the total mass of each zone is determined from the mass of the combusted fuel at the time of its generation and the requisite unburnt charge mass. The latest is determined from the corresponding zone fuel mass and the zone equivalence ratio $(\Phi)$. Along with zone mass, the value of $\Phi$ also affects zone volume, temperature, and chemical composition which in turn affect significantly the NO formation mechanism.

For NO formation, a constant value of $\Phi$ is used which is identical for all zones, instead of using a phenomenological

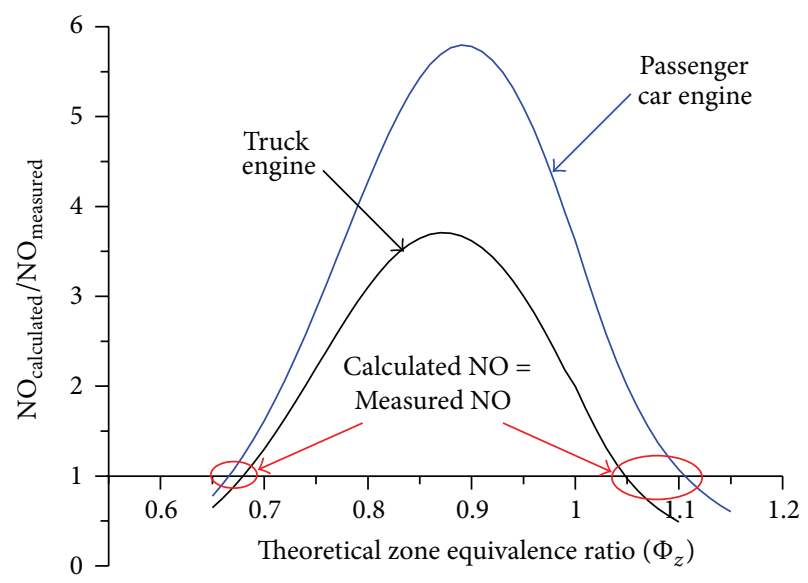

FIGURE 3: Variation of calculated/measured NO ratio with zone equivalent ratio $\Phi$.

spray model $[7,33]$ or empirical approaches for the determination of local air-entrainment rate [31, 32]. Although this concept does not correspond to the actual case of DI Diesel engines combustion, it has been adopted for low complexity and computational cost. Furthermore, it does not deviate significantly from reality since, during NO formation, the local $\Phi$ is close to stoichiometry (stoichiometric diffusion flame [45]). To evaluate the validity of this assumption (i.e., constant zone $\Phi$ ), a sensitivity analysis has been conducted to examine its effect on tailpipe $\mathrm{NO}$ values. Indicative results from this analysis (derived from the implementation of the model on the passenger car and truck engine examined in the present study) are depicted in Figure 3 where the variation of the calculated/measured NO ratio with zone $\Phi$ value is depicted.

As shown in Figure 3, tailpipe NO variation with zone $\Phi$ is similar for both engines examined. It is also revealed that NO formation is sensitive to zone $\Phi$. As observed from Figure 3, the predicted NO values coincide with the actual ones, for two different zone $\Phi$ values. However, as known, NO formation takes place close to stoichiometry $(\Phi=1)$. For this reason, the right-hand value (see Figure 3) of zone $\Phi$ is finally adopted. As noted, this value varies (slightly) with engine operating conditions, engine settings, and so forth. The previous assumption has been verified from the fact that optimum NO predictions have been observed when using $\Phi$ values ranging from 1.00 to 1.25 .

To estimate zone $\Phi$, for each operating point, an empirical correlation is used, which involves typical engine operating parameters and values derived from the measured cylinder pressure processing and HHR analysis. The aforementioned empirical correlation resulted from an extended multiple regression analysis involving numerous parameters related with $\mathrm{NO}$ formation. At this analysis, an elimination procedure ( $F$ and $t$ statistical tests [49-51]) was conducted at first to eliminate the less influencing parameters. Then, from the remaining parameters, the correlation for zone $\Phi$ described in (11) was extracted by using a weighted (bisquare) leastsquares-robust-fit regression method [51]. The comparison between the estimated (from (11)) and the $\Phi$ values that 
TABLE 1: Engine data.

\begin{tabular}{lcc}
\hline & Engine A & Engine B \\
\hline Number of cylinders & 6 & 4 \\
Bore [mm] & 102 & 88 \\
Stroke [mm] & 130 & 88.4 \\
Connecting rod length [mm] & 215 & 149 \\
Compression ratio & 18.5 & 18.0 \\
Displacement volume [lt] & 6.37 & 2.15 \\
Maximum brake power output & $205 \mathrm{~kW} @$ & $92 \mathrm{~kW} @$ \\
Inlet valve close [ ${ }^{\circ} \mathrm{CA}$ ATDC] & $2300 \mathrm{rpm}$ & $4200 \mathrm{rpm}$ \\
Exhaust valve open [ ${ }^{\circ} \mathrm{CA}$ & -171 & -123 \\
ATDC] & 121 & 135 \\
\hline
\end{tabular}

provide matching between experimental and calculated NO values (see Figure 3 ) presents an RMSE $=1.47 \%$ :

$$
\begin{aligned}
\Phi= & c_{0}+c_{1} \cdot\left(\frac{p_{\mathrm{IVC}}}{p_{\mathrm{amb}}}\right)^{-1}+c_{2} \cdot\left(\frac{p_{\mathrm{SOC}_{\text {main }}}}{p_{\mathrm{amb}}}\right)^{-1}+c_{3} \\
& \cdot \frac{p_{\mathrm{comb} \text { max }}}{p_{\mathrm{SOC}_{\text {main }}}}+c_{4} \cdot \frac{\mathrm{COC}}{\mathrm{TDC}}+c_{5} \cdot \Phi_{\text {eng. overall }}+c_{6} \\
& \cdot \frac{S_{p}}{S_{p_{\text {ref }}}}+c_{7} \cdot \frac{P}{P_{\text {ref }}}
\end{aligned}
$$

In the previous expression $\mathrm{SOC}_{\text {main }}$ corresponds to the $\mathrm{CA}\left[{ }^{\circ} \mathrm{CA} \mathrm{ABDC}\right]\left(\mathrm{BDC} \equiv 0^{\circ} \mathrm{CA}\right)$ of the main combustion commencement, $\mathrm{TDC}\left(\equiv 180^{\circ} \mathrm{CA} \mathrm{ABDC}\right)$ to top dead center, COC to center of combustion, and IVC to intake valve closure; $P$ and $S_{p}$ are the engine brake power output $[\mathrm{kW}]$ and mean piston speed $[\mathrm{m} / \mathrm{s}]$, respectively. The reference $P\left(P_{\text {ref }}\right)$ corresponds to the maximum engine brake power output (see Table 1$)$ and the reference $S_{p}\left(S_{p_{\text {ref }}}\right)$ equals $10[\mathrm{~m} / \mathrm{s}]$.

The first parameter $\left(p_{\mathrm{IVC}} / p_{\mathrm{amb}}\right)$ of (11) accounts for the effect of intake air pressure, while the second $\left(p_{\mathrm{SOC}_{\text {main }}} / p_{\mathrm{amb}}\right)$ accounts for the effect of compression ratio. The third one ( $\left.p_{\text {comb. max }} / p_{\mathrm{SOC}_{\text {main }}}\right)$ accounts for the effect of pressure derivative (pressure increase due to combustion which strongly affects NO formation) which is also related with SOI. The fourth parameter (COC/TDC) accounts for the effect of combustion duration. The fifth parameter $\left(\Phi_{\text {eng. overall }}\right)$ provides information for the overall air supply while the sixth $\left(S_{p} / S_{p_{\text {ref }}}\right)$ accounts for the effect of engine speed on fuelair mixing and available time for NO formation. Finally, the seventh parameter $\left(P / P_{\text {ref }}\right)$ accounts for the effect of engine load.

\section{Test Engine Description}

The present model is implemented on a heavy-duty truck engine (Engine A) and a light-duty passenger car engine (Engine B) to test its ability to predict NO emissions. Both engines are supercharged Diesels, equipped with a commonrail DI fuel injection system and a high pressure EGR system using EGR cooler. The defenses between the two tested engines are the following:

(1) In contrast with the truck engine, the passenger car engine uses pilot fuel injection, mainly to reduce engine noise.

(2) The truck engine has two additional cylinders and treble displacement volume compared to the car engine.

(3) Since the examined engines are designed for different operating areas, they have different fuel injection strategy (i.e., injection profile, timing, etc.) and valve timing. Furthermore, due to the high torque demand of the truck engine, it produces higher power output and operates at lower engine speeds.

The main data of the test engines are summarized in Table 1.

\section{Test Cases Examined}

In the present work, numerous measurements were used to evaluate the ability of the proposed model to predict NO emissions. The experimental measurements were provided by AVL and ETH during cooperation under an EU funded project. It is emphasized that the provided experimental measurements were tailpipe NO concentrations (measured using chemiluminescence analyzers able to provide both measurements: $\mathrm{NO}$ and total $\mathrm{NO}_{x}$ ) which, as mentioned (see Section 3.6), is usually the predominant of $\mathrm{NO}_{x}$ regarding Diesel engines.

The examined operating points for Engine A are categorized as follows:

(1) Operating points corresponding to the Extended European Stationary Cycle (EESC). The EESC includes seven load points for five engine speed cases (1400-2200 rpm), namely, 35 operating points.

As for the mid-speed and mid-load engine operation $(1800 \mathrm{rpm}$ and $86 \mathrm{~kW})$ the following cases are examined:

(2) SOI variation from -20 to $+10^{\circ} \mathrm{CA}$ ATDC.

(3) EGR rate variation from 2 to $18 \%$.

(4) Fuel injection pressure (rail pressure) variation from 1000 to 1400 bar.

(5) Inlet manifold pressure variation from 1.3 to 2 bar (abs.).

For Engine B, the following parameters are varied, considering three operating points, namely, $2000 \mathrm{rpm}$ and $29.4 \mathrm{~kW}$, $2500 \mathrm{rpm}$ and $18.3 \mathrm{~kW}$, and $2500 \mathrm{rpm}$ and $31.4 \mathrm{~kW}$ :

(1) EGR rate from 0 to $25 \%$.

(2) Fuel injection pressure from 500 to 1000 bar.

(3) SOI from -10 to $6^{\circ} \mathrm{CA}$ ATDC.

(4) Inlet manifold pressure from 1.1 to 1.7 bar (abs.)

Thus a total of 132 operating points were examined, 60 of which are attributed to Engine A and 72 to Engine B. 


\section{Results and Discussion}

\subsection{Heavy-Duty Truck Engine (Engine A)}

6.1.1. Prediction of NO at the EESC Operating Points. Initially the model was implemented on Engine A, for various operating points corresponding to the EESC, to predict NO emissions. The operating points of this cycle are defined by the engine load and speed. The SOI, EGR, fuel injection pressure, and intake manifold pressure settings were obtained from the ECU (default settings). The comparison of calculated and measured $\mathrm{NO}$ values against engine power for various speeds is presented in Figure 4.

As revealed from the observation of Figure 4, the proposed model is able to predict satisfactorily the NO trend with engine power. The trend is approximately linear and decreases with engine speed. A higher difference between calculated and measured absolute values for the highest loads can be also observed. This is mostly attributed to the highest in-cylinder pressure signal noise during expansion phase. The result is combustion duration overestimation and high heat release peeks causing increased NO formation.

6.1.2. NO Variation with Engine Settings. Next, the model's ability to capture the $\mathrm{NO}$ variation for different engine settings, namely, SOI, EGR rate, injection pressure, and intake manifold pressure variation, is examined. The results are depicted in Figure 5.

The observation of Figure 5 reveals that the model is capable of capturing both trend and absolute values of $\mathrm{NO}$ against the aforementioned settings. As shown, NO is exponentially reduced with injection retard (SOI). Furthermore, as shown, the increase of EGR rate induces linear reduction of NO. In addition, it is shown that the injection pressure increase induces a linear increase of NO. Likewise, a linear increase of $\mathrm{NO}$ with intake manifold pressure increase is observed.

\subsection{Light-Duty Passenger Car Engine (Engine B)}

6.2.1. NO Variation with EGR. Next, the ability of the proposed model to predict NO emissions for Engine B for various EGR rates is evaluated. In Figure 6, the comparison between predicted and measured $\mathrm{NO}$ values against EGR rate variation is depicted.

As shown in Figure 6, the model manages to predict the trend of NO variation with EGR rate which is approximately linear. Observing the higher load curves $(29.4 \mathrm{~kW}, 31.4 \mathrm{~kW})$, a small slope decrease can be noted as the speed increases from $2000 \mathrm{rpm}$ to $2500 \mathrm{rpm}$. Regarding engine operation at $2500 \mathrm{rpm}$, the curve slope significantly increases with engine load (i.e., $18.3 \mathrm{~kW}$ to $31.4 \mathrm{~kW}$ ). Furthermore, the most of the calculated absolute values are satisfactorily close to the measured ones.

6.2.2. NO Variation with Fuel Injection Pressure. The ability of the proposed model to capture the effect of fuel injection pressure on $\mathrm{NO}$ emissions is also evaluated. The comparison
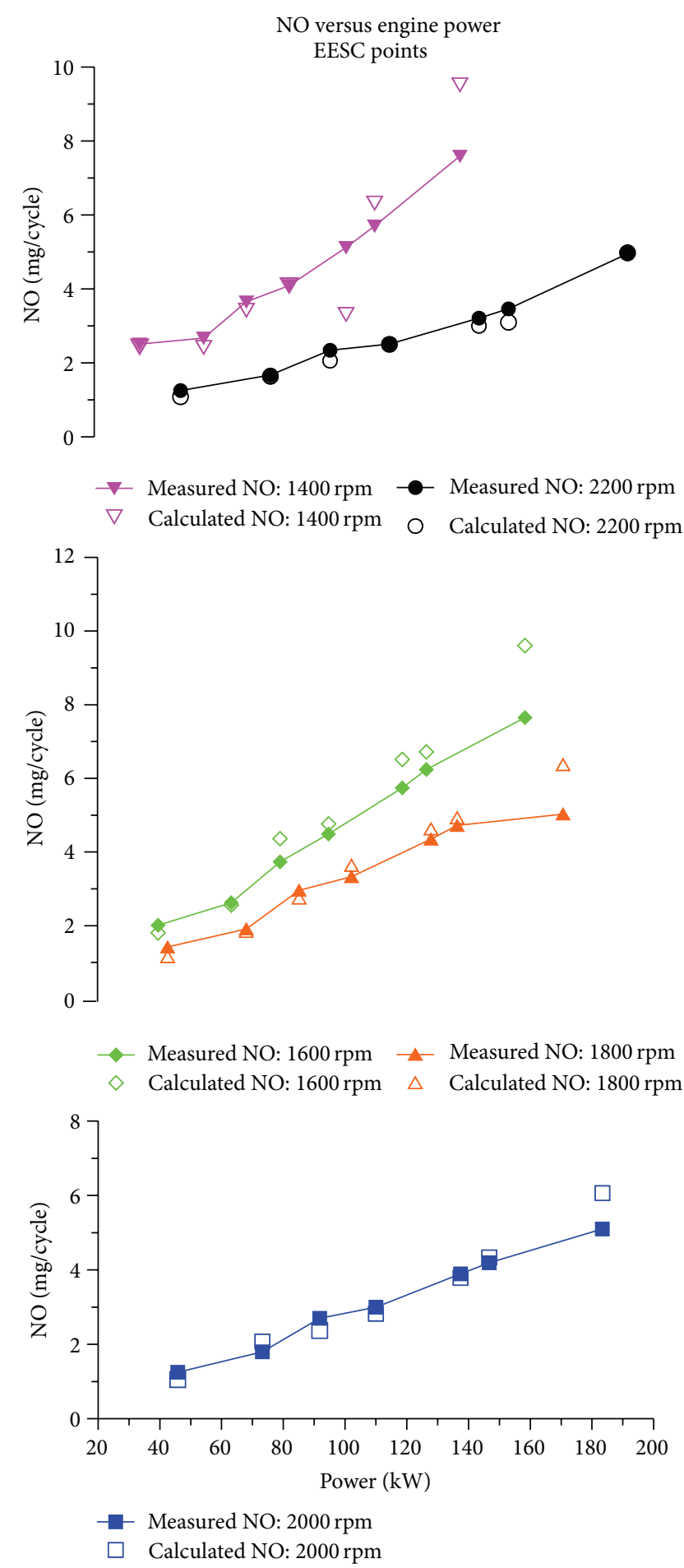

FIGURE 4: NO variation with engine power for various speeds (EESC points) for Engine A.

between measured and calculated NO values against injection pressure is depicted in Figure 7.

As shown in Figure 7, the model approaches fairly well the absolute NO values and trend which is slightly ascending and approximately linear. However, for some cases, the NO trend is not ideally captured, despite the fact that the absolute 


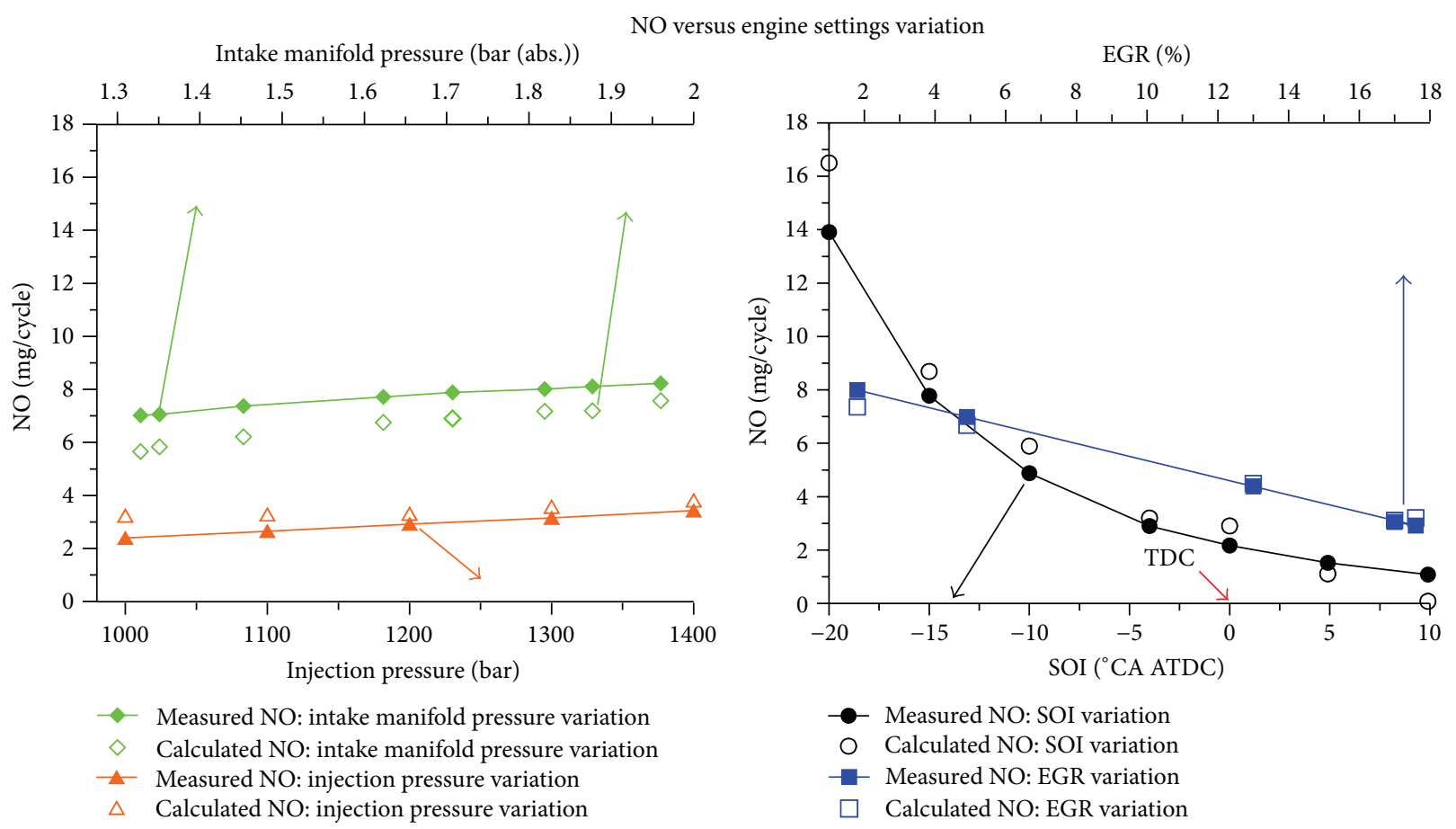

FIGURE 5: NO variation with SOI, EGR, injection pressure, and intake manifold pressure variation for Engine A at $1800 \mathrm{rpm}$ and $86 \mathrm{~kW}$.

calculated NO values are sufficiently close to the measured ones. This is mostly attributed to the relatively low absolute $\mathrm{NO}$ values and the slight variation of measured NO with injection pressure increase. Thus, even small inaccuracies of input data can induce noticeable divergence of the predicted values.

6.2.3. NO Variation with SOI. In this section, model's ability to predict the effect of SOI on $\mathrm{NO}$ emissions is evaluated. The variation of calculated and measured NO against SOI variation is presented in Figure 8.

From the observation of Figure 8, the ability of the model to predict NO trend with SOI variation is clearly proven. Absolute NO values are also adequately calculated. As shown, for the higher loads (29.4 and $31.4 \mathrm{~kW}$ ) the decrease of NO with SOI is more intensive. On the other hand, engine speed does not seem to affect the slope significantly. Referring to engine operation at $2500 \mathrm{rpm}$ and $18.3 \mathrm{~kW}$, both $\mathrm{NO}$ variation and absolute values are considerably low. For this reason, the model presents difficulties to accurately capture precisely the measured NO tendency despite the fact that it achieves to approach the absolute values satisfactorily.

6.2.4. NO Variation with Intake Manifold Pressure. Finally, the ability of the model to predict the effect of intake manifold pressure on NO is evaluated. The comparison between measured and calculated $\mathrm{NO}$ values against intake manifold pressure is depicted in Figure 9.

The observation of Figure 9 reveals that the model is able to approach adequately the NO trend with intake manifold pressure. As shown in Figure 9, the slope, which is practically linear and ascending, decreases with engine speed and increases with engine load. As shown, the calculated absolute $\mathrm{NO}$ values present a divergence from the respective measured ones which is possibly due to their very low values which induce high relative errors.

6.3. Statistical Analysis and Error Sources. At this point, an error analysis is presented. Namely, the relative (calc. $\mathrm{NO}_{x} /$ meas. $\left.\mathrm{NO}_{x}-1\right) \cdot 100$ and absolute (calc. $\mathrm{NO}$ - meas. $\mathrm{NO}$ ) errors have been calculated. In Table 2 the distribution of the test cases into relative error zones is shown.

Referring to Table 2, it should be noted that the high percentage (relative) error can be misleading because the very low absolute $\mathrm{NO}$ values induce high relative errors.

The main error sources are the following:

(i) inaccuracies of input data (normal) such as air and fuel mass flow rate, EGR rate, charge initial conditions, and in-cylinder pressure,

(ii) primary measurement error (e.g., NO measurements),

(iii) high cylinder pressure measurement signal error,

(iv) cylinder pressure processing (smoothing, differentiation),

(v) HRR processing and analysis,

(vi) miscalculation of the parameters used in (11) which provides the zone $\Phi$ (due to the previous),

(vii) computational errors (e.g., convergence, rounding, $\mathrm{CA}$, and zonal discretization). 


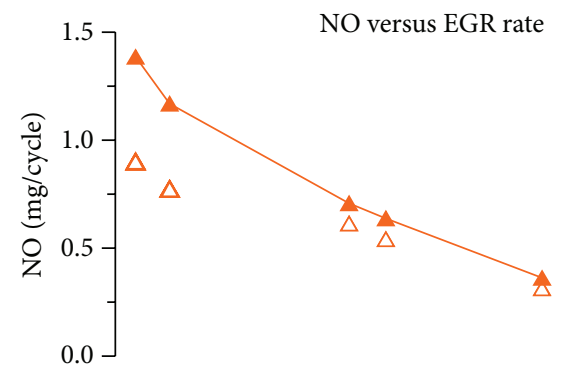

$\triangle$ Calculated NO: $2500 \mathrm{rpm}, 31.4 \mathrm{~kW}$

- Measured NO: $2500 \mathrm{rpm}, 31.4 \mathrm{~kW}$

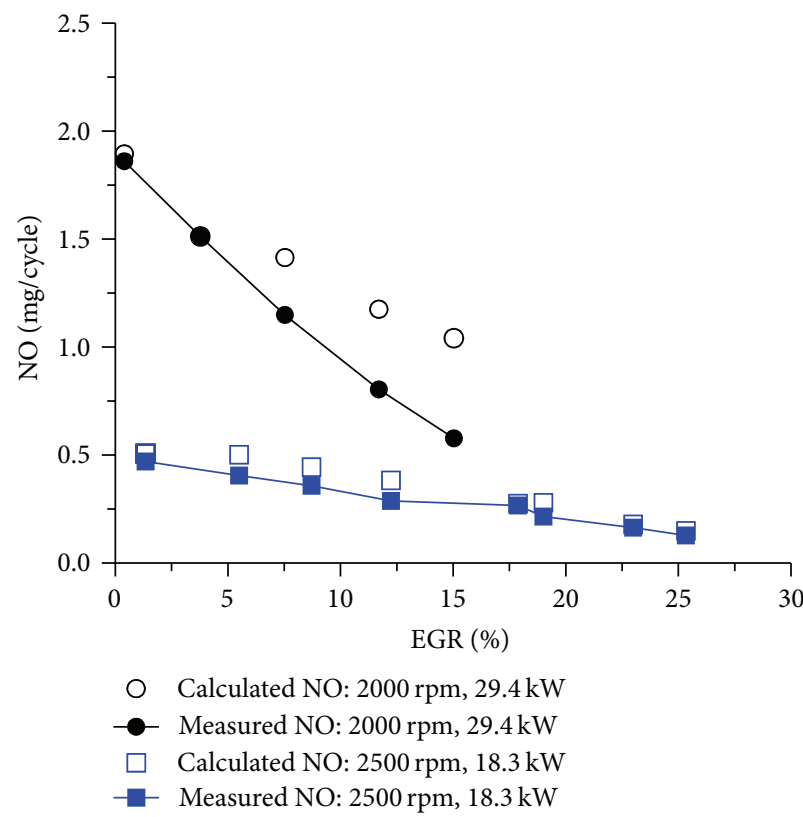

FIGURE 6: NO variation with EGR rate for three operating points of Engine B.

TABLE 2: Percentage of test cases which correspond to a specific relative error zone.

\begin{tabular}{|c|c|c|c|c|c|c|c|c|}
\hline \multirow{3}{*}{ Rel. error zone $[ \pm \%]$} & \multicolumn{4}{|c|}{ Engine A } & \multicolumn{4}{|c|}{ Engine $\mathrm{B}$} \\
\hline & Test cases & & Abs. error $( \pm)$ & & Test cases & & Abs. error $( \pm)$ & \\
\hline & {$[\%]$} & {$[\mathrm{mg} / \mathrm{cycle}]$} & [g/kg_fuel] & [g/kWh] & [\%] & {$[\mathrm{mg} /$ cycle $]$} & [g/kg_fuel] & {$[\mathrm{g} / \mathrm{kWh}]$} \\
\hline $0-5$ & 22 & 0.2 & 0.4 & 0.1 & 26 & 0.02 & 0.3 & 0.1 \\
\hline $0-10$ & 42 & 0.3 & 0.9 & 0.2 & 43 & 0.04 & 0.5 & 0.1 \\
\hline $0-15$ & 68 & 0.7 & 1.9 & 0.4 & 57 & 0.07 & 0.9 & 0.2 \\
\hline $0-20$ & 83 & 1.0 & 2.8 & 0.6 & 67 & 0.09 & 1.1 & 0.3 \\
\hline $0-25$ & 87 & 1.1 & 2.8 & 0.6 & 78 & 0.14 & 2.2 & 0.5 \\
\hline $0-30$ & 93 & 1.4 & 3.4 & 0.7 & 79 & 0.20 & 2.2 & 0.5 \\
\hline $0-35$ & 95 & 1.9 & 3.5 & 0.8 & 89 & 0.35 & 3.4 & 0.8 \\
\hline $0-40$ & 98 & 2.0 & 4.0 & 0.9 & 89 & 0.37 & 3.4 & 0.8 \\
\hline $0-50$ & 98 & 2.0 & 4.0 & 0.9 & 93 & 0.45 & 4.2 & 1.0 \\
\hline
\end{tabular}

Nevertheless, as shown, the proposed model predicts the tailpipe NO emissions with acceptable relative error for the most test cases examined, as shown in Table 2 without further calibration (i.e., use of a correction multiplier). The overall comparison between calculated and measured $\mathrm{NO}$ values is presented in Figure 10 revealing promising model's predictive capability.

6.4. Computational Time. One of the major aims of the proposed model is the low computational cost. Namely, 

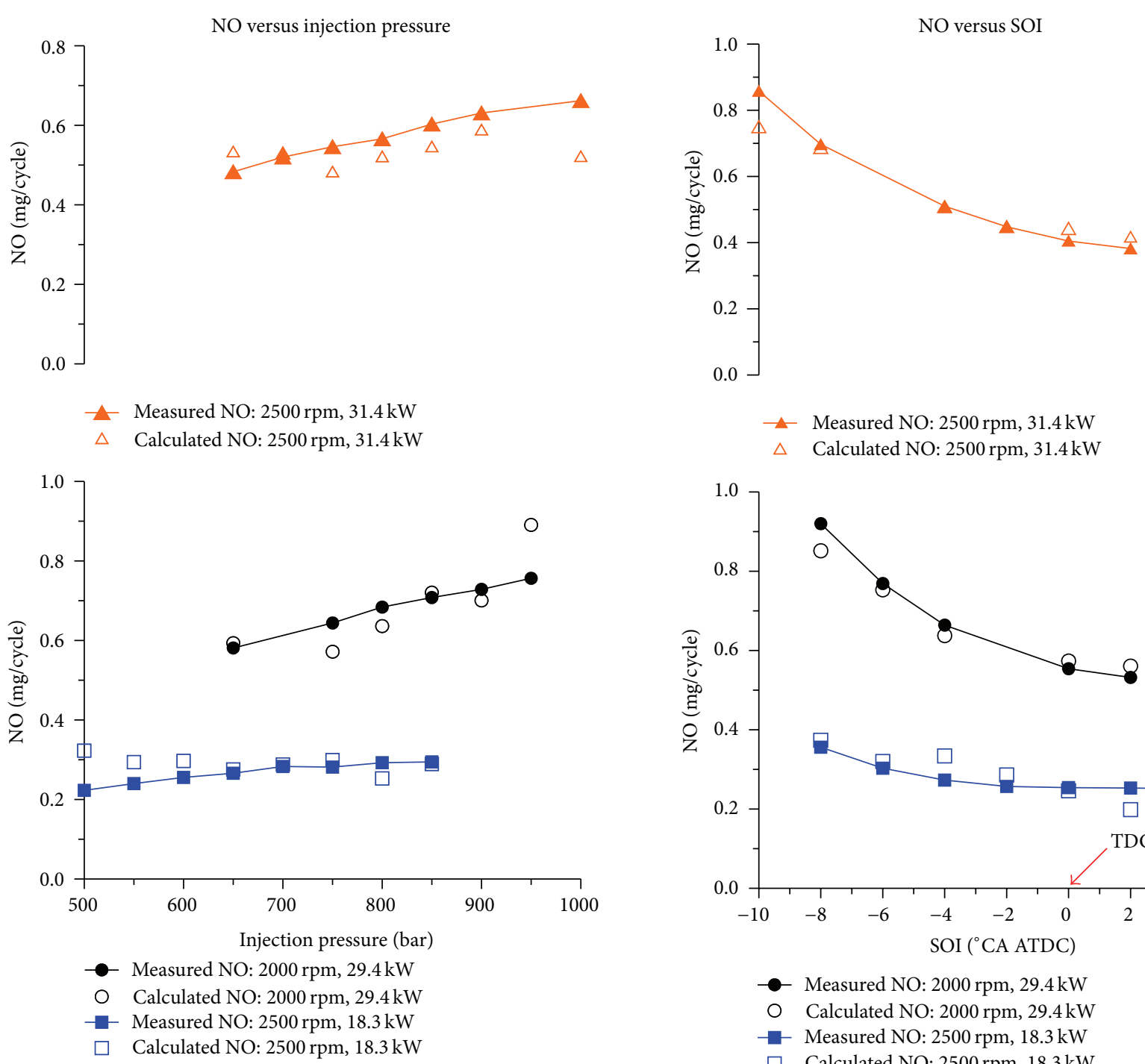

FIGURE 7: NO variation with injection pressure for three operating points of Engine $B$.

the model intends to provide reliable results very fast and specifically in a time period close to an engine cycle duration. This feature enables the use of the model in on-board and real-time applications. To achieve such low computational time the model should be embedded in specialized computer systems (FPGA, ASIC, microcontrollers, etc.) which are designed for these applications and are much faster than PCs.

However, in the present study model's computational time was evaluated by using a PC in order to detect the possibilities to diminish run time. The most important factor that affects the computational cost is the calculation timestep which, among the combustion duration, determines the number of the zones. To examine the effect of time-step on computational time, a sensitivity analysis was conducted, indicative results of which are depicted in Figure 11.

As revealed from Figure 11, the computational time decreases exponentially with the increase of calculation timestep without significant variation of the relative error. Hence,

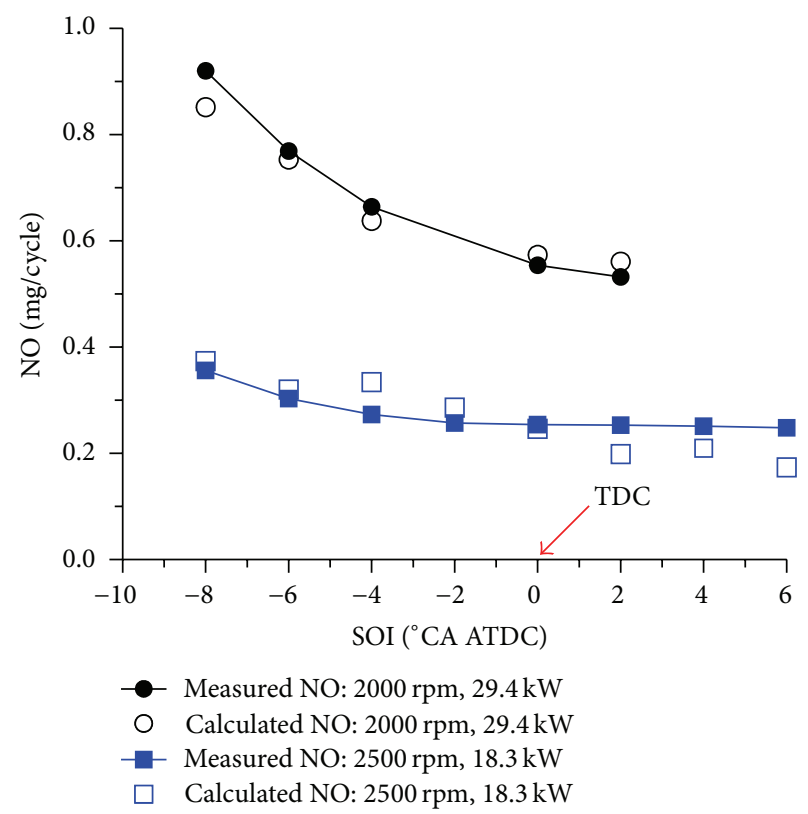

FIGURE 8: NO variation with SOI for three operating points of Engine B.

a strong potential exists for the model, to be a reliable realtime tool that can contribute to the endeavor for $\mathrm{NO}_{x}$ control.

\section{Summary and Conclusions}

The demand for compliance with the continuously stringent exhaust emissions regulations [2] compels ICE industry to limit $\mathrm{NO}_{x}$ emissions. For this reason, DI Diesel engine manufactures are strongly interested for the development of efficient technologies/methodologies for $\mathrm{NO}_{x}$ emissions control. To minimize the development cost, experimental effort, fuel consumption penalty, and after-treatment equipment addition, computational models can be employed. These models should be fast, reliable at a wide range of implementation (i.e., various operating conditions and engine settings/adjustments), and applicable, without significant modifications, on different types of engines. 

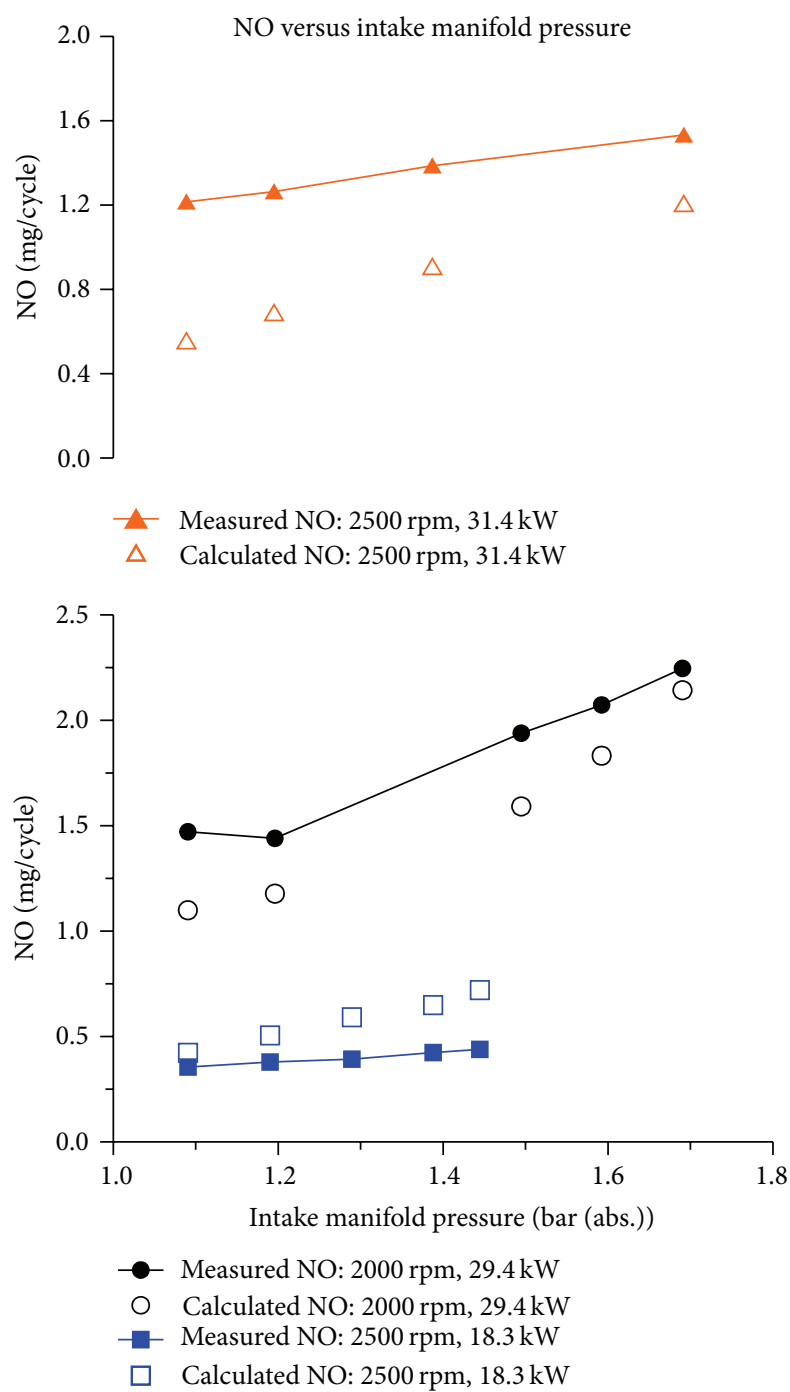

FIGURE 9: NO variation with intake manifold pressure for three operating points of Engine B.

Considering the previous necessity, a new, semiempirical, zero-dimensional multizone model for $\mathrm{NO}$ emissions prediction has been presented and validated on an extended range of operating conditions (132 test cases), on two different Diesel engine types, representative of the automotive sector.

The goal of the present work is the successful combination of physical and empirical concepts to develop a simplified model with NO predictive capabilities when implemented on different DI Diesel engines and various engine settings. As revealed from the presented investigation, the proposed model is capable to capture adequately the effect of engine load/speed, SOI, EGR rate, fuel injection pressure, and intake manifold pressure on $\mathrm{NO}$ emissions. NO trends and absolute values are predicted satisfactorily despite the very low values of some test cases. Most important is that the proposed model, due to its physical base and the use of measured parameters and a statistical correlation, achieves adequate NO predictions, avoiding the use of phenomenological spray models and/or geometrical discretization, targeting on

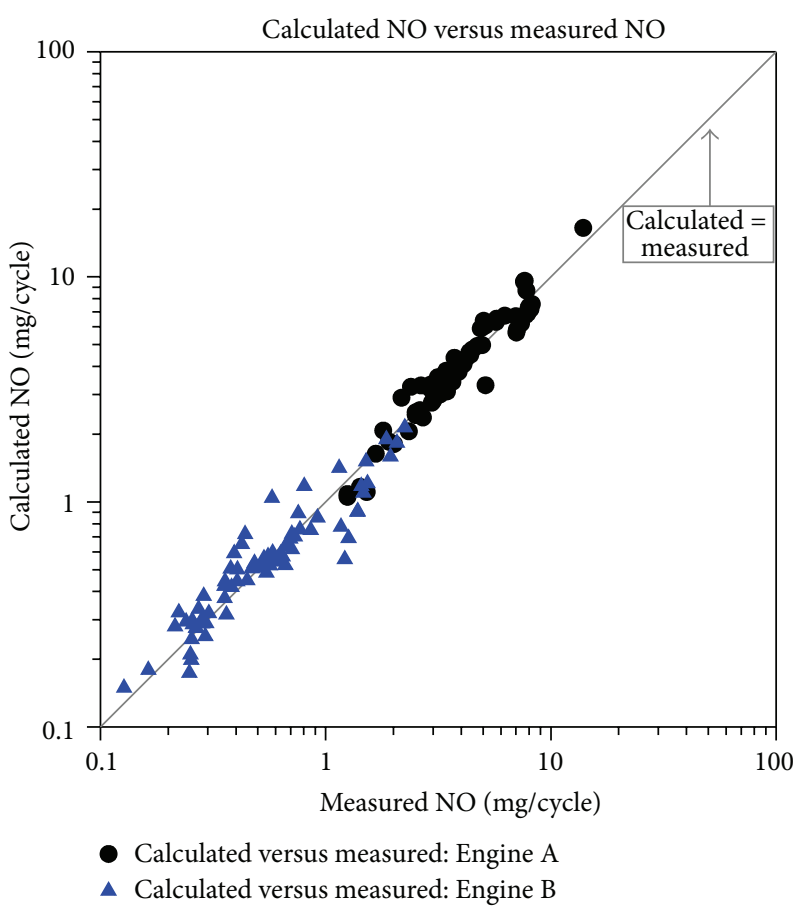

Figure 10: Overall comparison between calculated and measured NO for Engine A and Engine B.

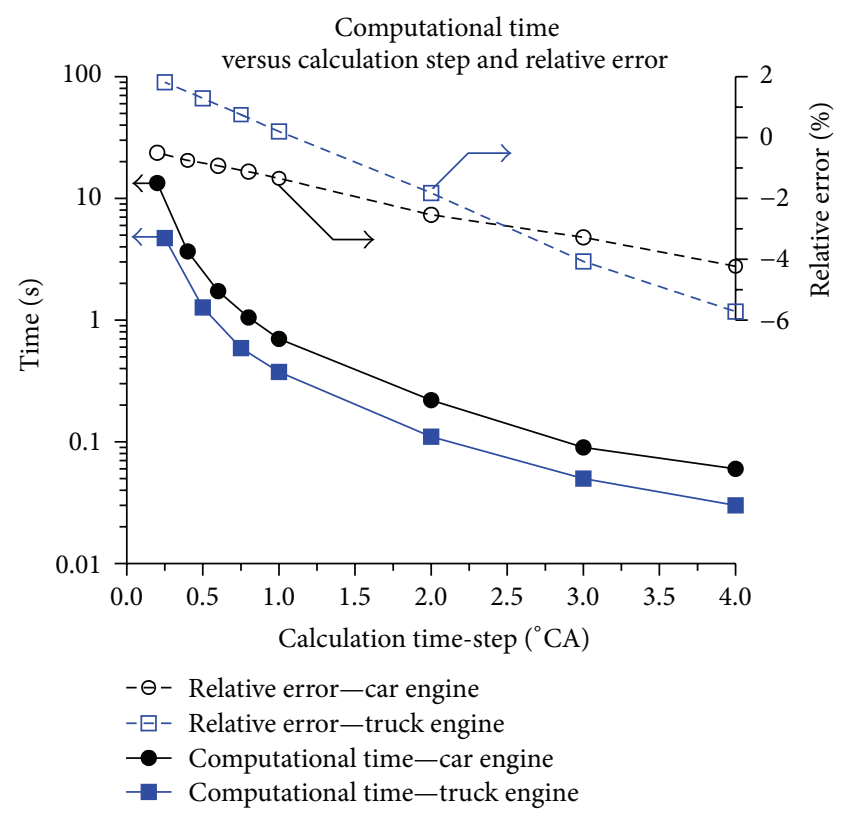

FIGURE 11: Effect of calculation time-step on computational time and relative error.

model's simplicity, low computational cost, and minimum calibration effort.

Model's predictive ability is enhanced from its robust physical background and the use of the actual pressure inside the cylinder from which the processes taking place during the close engine cycle affect NO formation and are directly or implicitly accounted for. The measurement of 
cylinder pressure is currently standard practice for lab investigations and marine applications, but the perspective exists for its implementation in production vehicles in the near future. Furthermore, the parameters used in the empirical correlation for the zone $\Phi$ calculation are strongly related with NO formation and, along with the use of cylinder pressure, provide versatility to the model (i.e., expanding its implementation range).

Hence, the NO emissions prediction model presented herein can become a useful tool for ICE industry and researchers, after additional development and validation, for the following:

(1) Contribution to the development or/and real-time control of the in-cylinder (primary) NO abatement technologies/methodologies (e.g., model-based control).

(2) Contribution to the management of $\mathrm{NO}_{x}$ after-treatment systems.

(3) Contribution to the field of engine research, development, and optimization regarding $\mathrm{NO}_{x}$ control on existing engines (i.e., improvement of injection strategy, EGR rate, etc.).

\section{Nomenclature}

ABDC: After bottom dead center

ATDC: After top dead center

CA: Crank angle

CFD: Computational flow dynamics

COC: Center of combustion

cp: $\quad$ Constant pressure specific heat capacity $[\mathrm{J} / \mathrm{kmol} / \mathrm{K}]$

$d H_{\text {sens }}$ : Sensible enthalpy difference between reactants and combustion products

DI: Direct injection

$d Q: \quad$ Energy (heat) differential [J]

ECU: Engine control unit

EESC: Extended European Stationary Cycle

EGR: Exhaust gas recirculation

EVO: Exhaust valve open

$h$ : $\quad$ Specific enthalpy $[\mathrm{J} / \mathrm{kmol}]$ or $[\mathrm{J} / \mathrm{kg}]$

$H: \quad$ Total enthalpy [J]

$H_{\text {sens }}$ : Sensible enthalpy $\left(H_{\text {sens }}(T)=H(T)-H\left(25^{\circ} \mathrm{C}\right)\right)$ [J]

HRR: Heat release rate

ICE: Internal combustion engine

IVC: Intake valve closure [ ${ }^{\circ} \mathrm{CA}$ ATDC]

LHV: Lower heating value $[\mathrm{J} / \mathrm{kg}]$

$m: \quad$ Mass $[\mathrm{kg}]$

MW: Molecular weight $[\mathrm{kg} / \mathrm{kmol}]$

$N: \quad$ Engine speed [rpm]

$n$ : Number of moles [kmole]

$n_{\text {cyl }}: \quad$ Number of cylinders [-]

$P: \quad$ Power $[\mathrm{kW}]$

$p: \quad$ Pressure $[\mathrm{Pa}]$

p IM: Intake manifold pressure [bar (abs)]

$R: \quad$ Reaction rates $\left[\mathrm{kmol} / \mathrm{m}^{3} / \mathrm{s}\right]$

RG: Residual gas
RMSE: Root mean square error

SOC: Start of combustion

SOI: Start of injection

$S_{p}: \quad$ Mean piston speed $[\mathrm{m} / \mathrm{s}]$

T: $\quad$ Temperature [K]

TDC: Top dead center

$V: \quad$ Volume $\left[\mathrm{m}^{3}\right]$.

Greek Symbols

$\triangle \mathrm{CA}$ : Crank angle step $\left[{ }^{\circ}\right]$

$\Phi: \quad$ Equivalence ratio $[-]$.

Subscripts

$b$ : Burnt

cyl: Cylinder

$e$ : Equilibrium

$f:$ Fuel

$i$ : $\quad i$ th cylinder, $i$ th crank angle, and $i$ th operating point

IA: Intake air

$k$ : $k$ th iteration

$p$ : Products

$r$ : Reactants

tr: Trapped

ub: Unburnt

$z$ : Zone order number.

\section{Conflict of Interests}

The authors declare that there is no conflict of interests regarding the publication of this paper.

\section{Acknowledgments}

Many thanks are attributed to Alexander S. Onassis Public Benefit Foundation for providing to the first author a full scholarship (Grant no. GZG037/2010-2011). Authors also thank AVL and ETH for the supply of the experimental data, which were provided as part of the EU funded I.P. "Green Heavy Duty Engine.”

\section{References}

[1] A. C. Lloyd and T. A. Cackette, "Diesel engines: environmental impact and control," Journal of the Air and Waste Management Association, vol. 51, no. 6, pp. 809-847, 2001.

[2] Diesel Net, 1997-2015, https://www.dieselnet.com/standards/.

[3] T. V. Johnson, "Review of diesel emissions and control," International Journal of Engine Research, vol. 10, no. 5, pp. 275-285, 2009.

[4] N. S. Savva and D. T. Hountalas, "Evolution and application of a pseudo-multi-zone model for the prediction of NOx emissions from large-scale diesel engines at various operating conditions," Energy Conversion and Management, vol. 85, pp. 373-388, 2014.

[5] H. Hiroyasu, "Diesel engine combustion and its modeling," in Proceedings of the 1st International Symposium on Diagnostics and Modeling of Combustion in Internal Combustion Engines, Tokyo, Japan, 1985. 
[6] D. Jung and D. N. Assanis, "Multi-zone DI diesel spray combustion model for cycle simulation studies of engine performance and emissions," SAE Technical Paper 2001-01-1246, 2001.

[7] D. T. Hountalas, D. Kouremenos, G. Mavropoulos et al., "Multizone combustion modelling as a tool for DI diesel engine development-application for the effect of Injection pressure," SAE Paper, SAE International, 2004.

[8] R. D. Reitz and C. J. Rutland, "Development and testing of diesel engine CFD models," Progress in Energy and Combustion Science, vol. 21, no. 2, pp. 173-196, 1995.

[9] G. Li and S. M. Sapsford, CFD Simulation of HSDI Engine Combustion Using VECTIS, Ricardo Consulting Engineer's, Shoreham-by-Sea, UK, 2003.

[10] I. Arsie, C. Pianese, M. Sorrentino et al., "A single-zone model for combustion and NOx simulation in common-rail multijet Diesel engines," in Proceedings of the 6th International Conference on Engines for Automobile, Capri, Italy, September 2003.

[11] S. Awad, E. G. Varuvel, K. Loubar, and M. Tazerout, "Single zone combustion modeling of biodiesel from wastes in diesel engine," Fuel, vol. 106, pp. 558-568, 2013.

[12] H. Yasar, H. S. Soyhan, H. Walmsley, B. Head, and C. Sorusbay, "Double-Wiebe function: an approach for single-zone HCCI engine modeling," Applied Thermal Engineering, vol. 28, no. 1112, pp. 1284-1290, 2008.

[13] S. Provataris, N. S. Savva, and D. T. Hountalas, "Detailed evaluation of a new semi-empirical two-zone nox model by application on various diesel engine configurations," in Proceedings of the ASME Internal Combustion Engine Division Spring Technical Conference, pp. 727-743, ASME, Torino, Italy, May 2012.

[14] C. Ericson, B. Westerberg, M. Andersson, and R. Egnell, "Modelling diesel engine combustion and NOx formation for model based control and simulation of engine and exhaust aftertreatment systems," SAE Technical Paper 2006-01-0687, 2006.

[15] C. Wilhelmsson, P. Tunestål, B. Widd, and R. Johansson, "A physical two-zone $\mathrm{NO}_{x}$ model intended for embedded implementation," SAE Technical Paper 2009-01-1509, 2009.

[16] M. Andersson, B. Johansson, A. Hultqvist, and C. Noehre, "A predictive real time NOx model for conventional and partially premixed Diesel combustion," SAE Paper, SAE International, 2006.

[17] X. Xue and J. A. Caton, "Nitric oxide and soot emissions determined from a multi-zone thermodynamic direct-injection diesel engine combustion model," International Journal of Engine Research, vol. 15, no. 2, pp. 135-152, 2014.

[18] R. Finesso and E. Spessa, "A real time zero-dimensional diagnostic model for the calculation of in-cylinder temperatures, HRR and nitrogen oxides in diesel engines," Energy Conversion and Management, vol. 79, pp. 498-510, 2014.

[19] M. Hirsch, K. Oppenauer, and L. del Re, "Dynamic engine emission models," in Automotive Model Predictive Control, L. del Re, F. Allgöwer, L. Glielmo, C. Guardiola, and I. Kolmanovsky, Eds., vol. 402 of Lecture Notes in Control and Information Sciences, pp. 73-78, Springer, 2010.

[20] H. Sequenz and R. Isermann, "Emission model structures for an implementation on engine control units," in Proceedings of the 18th IFAC World Congress, pp. 11851-11856, Milano, Italy, September 2011.

[21] C. Guardiola, B. Pla, D. Blanco-Rodriguez, and L. Eriksson, "A computationally efficient Kalman filter based estimator for updating look-up tables applied to NOx estimation in diesel engines," Control Engineering Practice, vol. 21, no. 11, pp. 14551468, 2013.

[22] J. Arregle, J. López, C. Guardiola, and C. Monin, "Sensitivity study of a NOx estimation model for on-board applications," SAE Paper 2008-01-0640, SAE International, 2008.

[23] C. Guardiola, J. J. López, J. Martín, and D. García-Sarmiento, "Semiempirical in-cylinder pressure based model for NOX prediction oriented to control applications," Applied Thermal Engineering, vol. 31, no. 16, pp. 3275-3286, 2011.

[24] J. Asprion, O. Chinellato, and L. Guzzella, "A fast and accurate physics-based model for the NOx emissions of Diesel engines," Applied Energy, vol. 103, pp. 221-233, 2013.

[25] W. Park, J. Lee, K. Min, J. Yu, S. Park, and S. Cho, "Prediction of real-time NO based on the in-cylinder pressure in Diesel engines," Proceedings of the Combustion Institute, vol. 34, no. 2, pp. 3075-3082, 2013.

[26] K. Murić, O. Stenlåås, and P. Tunestål, "Zero-dimensional modeling of $\mathrm{NO}_{x}$ formation with least squaresinterpolation," International Journal of Engine Research, 2013.

[27] S. D’Ambrosio, R. Finesso, L. Fu, A. Mittica, and E. Spessa, "A control-oriented real-time semi-empirical model for the prediction of NOx emissions in diesel engines," Applied Energy, vol. 130, pp. 265-279, 2014.

[28] D. T. Hountals, N. Savva, and R. G. Papagiannakis, "Development of a new physically based semi-empirical NOx model using the measured cylinder pressure," in Proceedings of the THIESEL Conference on Thermo- and Fluid Dynamic Processes in Diesel Engines, CMT, Valencia, Spain, 2010.

[29] N. Savva and D. Hountalas, "Detailed evaluation of a new semiempirical multi-zone $\mathrm{NO}_{x}$ model by application on various Diesel engine configurations," SAE Technical Paper 2012-011156, 2012.

[30] X. L. J. Seykens, Development and validation of a phenomenological diesel engine combustion model [Ph.D. thesis], Eindhoven University of Technology, Eindhoven, The Netherlands, 2010.

[31] G. A. Weisser, Modelling of combustion and nitric oxide formation for medium-speed DI diesel engines: a comparative evaluation of zero-and three-dimensional approaches [Ph.D. thesis], Swiss Federal Institute of Technology, Zürich, Switzerland, 2001.

[32] F. Diotallevi, Development of a Multi-Zone Model for NOx Formation in Diesel Engines, KTH Industrial Engineering and Management, Stockolm, Sweden, 2007.

[33] H. Hiroyasu, T. Kadota, and M. Arai, "Development and use of a spray combustion modeling to predict diesel engine efficiency and pollutant emissions: part 1 combustion modeling," Bulletin of JSME, vol. 26, pp. 569-575, 1983.

[34] J. B. Heywood, Internal Combustion Engine Fundamentals, vol. 930, McGraw-Hill, New York, NY, USA, 1988.

[35] J. M. Desantes, J. Galindo, C. Guardiola, and V. Dolz, "Air mass flow estimation in turbocharged diesel engines from incylinder pressure measurement," Experimental Thermal and Fluid Science, vol. 34, no. 1, pp. 37-47, 2010.

[36] B. Youssef, F. Guillemin, G. Le Solliec, and G. Corde, "In cylinder trapped mass estimation in diesel engines using cylinder pressure measurements," in Proceedings of the IEEE International Conference on Control Applications (CCA '11), pp. 561-566, IEEE, Denver, Colo, USA, September 2011.

[37] W. J. D. Annand, "Heat transfer in the cylinders of reciprocating internal combustion engines," Proceedings of the Institution of Mechanical Engineers, vol. 177, no. 1, pp. 973-996, 1963. 
[38] G. Woschni, "A universally applicable equation for the instantaneous heat transfer coefficient in the internal combustion engine," SAE Paper 670931, SAE International, 1967.

[39] R. W. Hamming, "Newton's method," in Numerical Methods for Scientists and Engineers, pp. 68-70, Dover, New York, NY, USA, 1973.

[40] G. A. Lavoie, J. B. Heywood, and J. C. Keck, "Experimental and theoretical study of nitric oxide formation in internal combustion engines," Combustion Science and Technology, vol. 1, no. 4, pp. 313-326, 1970.

[41] H. Cakir, "Nitric oxide formation in diesel engines," in Proceedings of the Institution of Mechanical Engineers, vol. 188, pp. 477483, 1974.

[42] C. W. Vickland, F. Strange, R. Bell, and E. Starkman, "A consideration of the high temperature thermodynamics of internal combustion engines," SAE Paper 620564, SAE International, 1962.

[43] R. J. B. Way, "Methods for determination of composition and thermodynamic properties of combustion products for internal combustion engine calculation," Procidings of IMechE, vol. 190, no. 1, pp. 687-697, 1976.

[44] C. D. Rakopoulos, D. T. Hountalas, E. I. Tzanos, and G. N. Taklis, "A fast algorithm for calculating the composition of diesel combustion products using an eleven species chemical equilibrium scheme," Advances in Engineering Software, vol. 19, no. 2, pp. 109-119, 1994.

[45] J. E. Dec, "A conceptual model of DI diesel combustion based on laser-sheet imaging," SAE Technical Paper 970873, 1997.

[46] Y. B. Zeldovich, "The oxidation of nitrogen in combustion and explosions," Acta Physicochimica URSS, vol. 21, no. 4, pp. 577$628,1946$.

[47] Y. B. Zeldovich, D. Frank-Kamenetskii, and P. Sadovnikov, Oxidation of Nitrogen in Combustion, Publishing House of the Acad of Sciences of USSR, 1947.

[48] R. K. Hanson and S. Salimian, "Survey of rate constants in H/N/O systems," in Combustion Chemistry, pp. 361-421, Springer, Berlin, Germany, 1984.

[49] G. A. Seber and A. J. Lee, Linear Regression Analysis, vol. 936, John Wiley \& Sons, Hobogen, NJ, USA, 2012.

[50] Microsoft, Excel 2013: Analysis Toolpack, 2013.

[51] MathWorks, MATLAB, MathWorks, Natick, Mass, USA, 2013. 


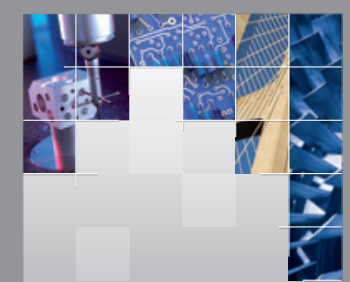

\section{Enfincering}
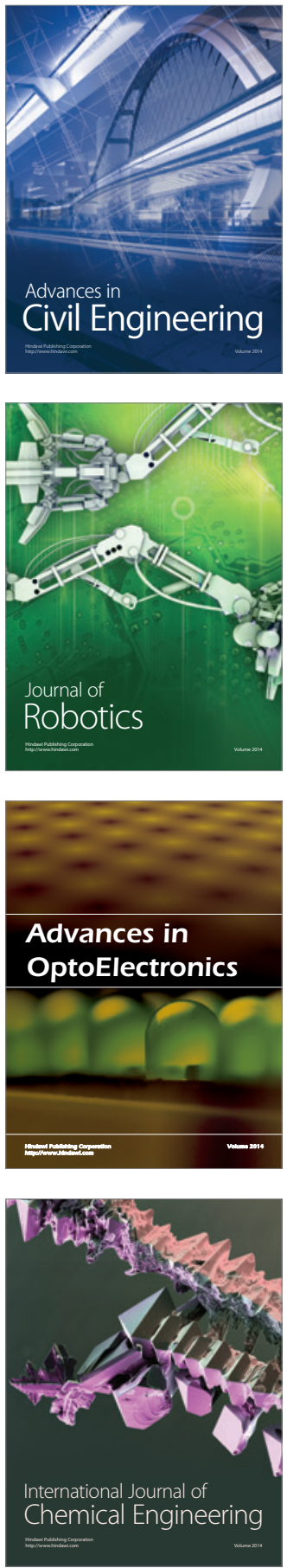

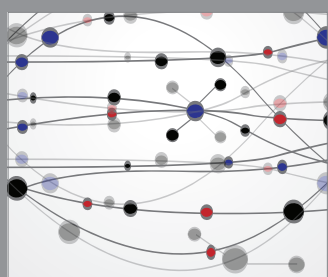

The Scientific World Journal

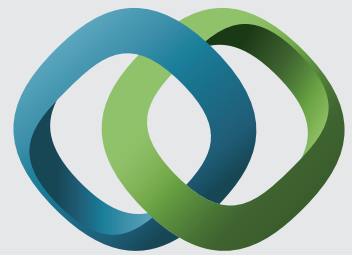

\section{Hindawi}

Submit your manuscripts at

http://www.hindawi.com
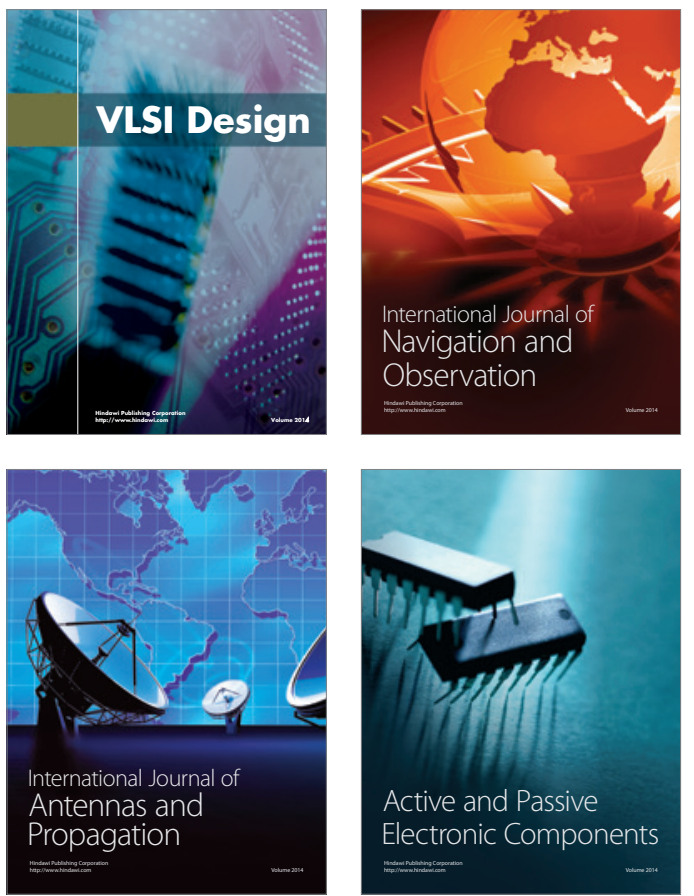
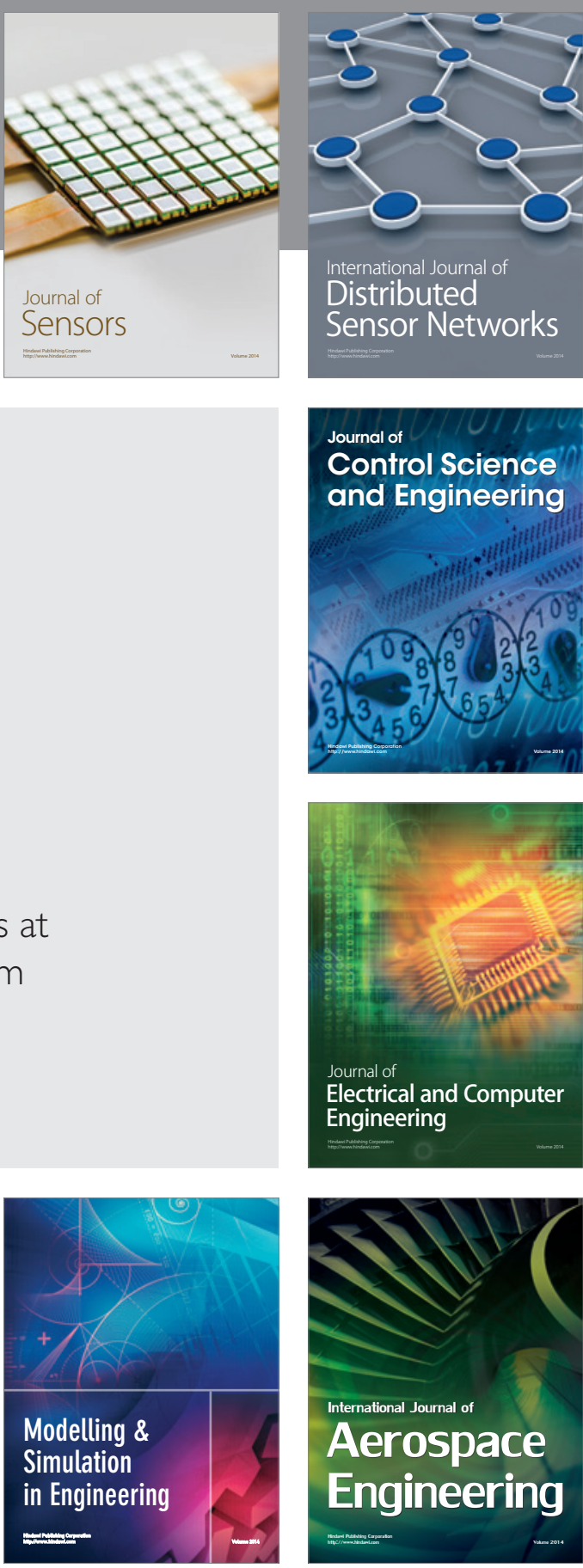

International Journal of

Distributed

Sensor Networks

Journal of

Control Science

and Engineering
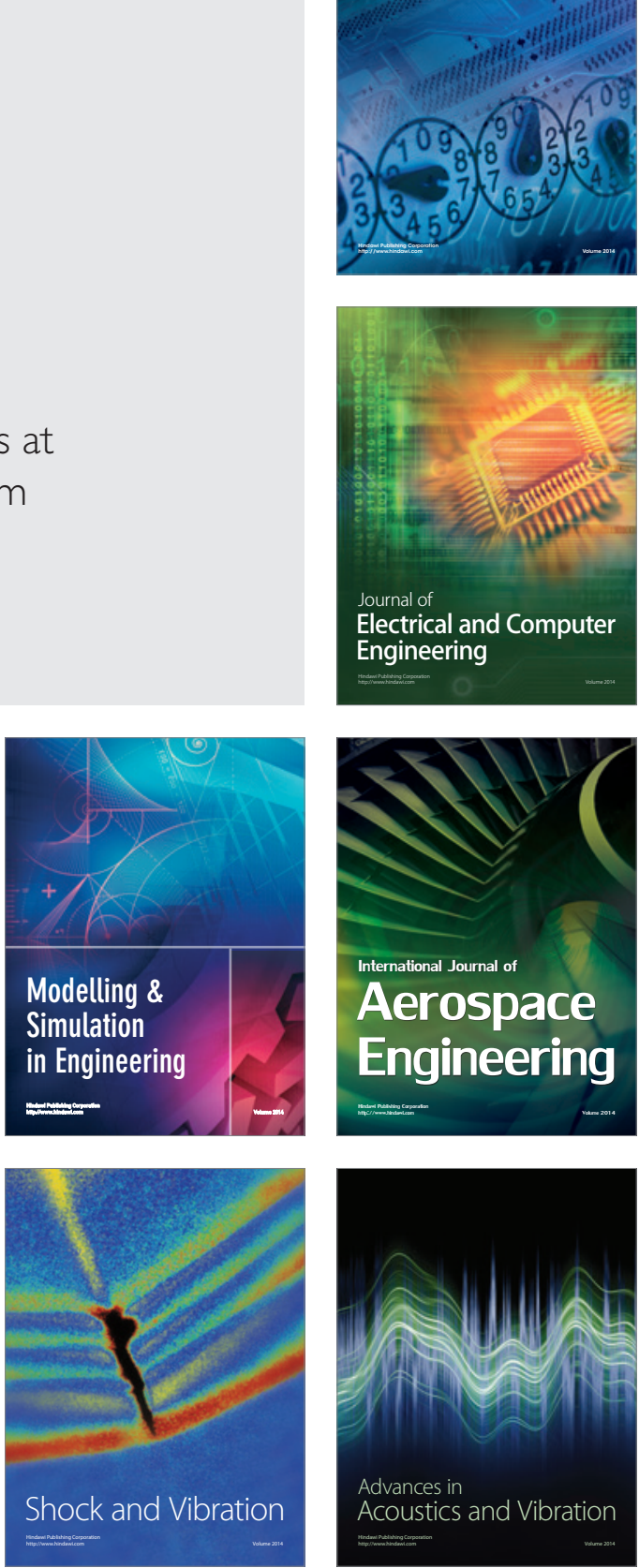